\title{
Role of tonic inhibition in associative reward conditioning in Lymnaea
}

\author{
Vincenzo Marra ${ }^{1}$, Ildikó Kemenes' ${ }^{1}$ Dimitris Vavoulis' ${ }^{2}$, Jianfeng Feng ${ }^{2}$, Michael O’Shea ${ }^{1}$ and Paul R. Benjamin ${ }^{1}$ \\ Sussex Centre for Neuroscience, School of Life Sciences, University of Sussex, Brighton, East Sussex, UK \\ 2 Department of Computer Science, University of Warwick, Coventry, UK
}

Edited by:

Martin Giurfa, Université Paul Sabatier-Toulouse III, France

\section{Reviewed by:}

Martin Giurfa, Université Paul Sabatier-Toulouse III, France David L. Glanzman, University of California at Los Angeles, USA

\section{*Correspondence:}

Vincenzo Marra, School of Life Sciences, University of Sussex, Brighton BN1 9QG, UK.

e-mail:v.marra@sussex.ac.uk
Changes in the strength of excitatory synaptic connections are known to underlie associative memory formation in the molluscan nervous system but less is known about the role of synaptic inhibition. Tonic or maintained synaptic inhibition has an important function in controlling the Lymnaea feeding system and is known to suppress feeding in the absence of food or in satiated animals. Tonic inhibition to the feeding network is provided by the N3t interneuron that has inhibitory monosynaptic connection with the central pattern generator interneuron, the N1M. Here we asked whether a reduction in the level of tonic inhibition provided by the N3t cell could play a role in reward conditioning? Semi-intact preparations made from hungry snails were conditioned using a previously developed one-trial chemical conditioning paradigm. We recorded electrical activity in a feeding motoneuron, the B3, at various time-points after conditioning. This allowed us to measure the frequency of spike activity in the N3t interneuron and monitor fictive feeding patterns that generate the rhythmic movements involved in food ingestion. We show that there is a reduction in N3t spiking at 1, 2, 3, and $4 \mathrm{~h}$ after conditioning but not at 10 and $30 \mathrm{~min}$ and the reduction in N3t firing inversely correlates with an increase in the conditioned fictive feeding response. Computer simulation of N3t-N1M interactions suggests that changes in N3t firing are sufficient to explain the increase in the fictive feeding activity produced by conditioning. A network model is presented that summarizes evidence suggesting that reward conditioning in Lymnaea is due to the combined effects of reduced tonic inhibition and enhanced excitatory synaptic connections between the CS pathway and feeding command neurons.

Keywords: reward classical conditioning, tonic inhibition, molluscan learning, modulation

\section{INTRODUCTION}

Modification in the strength of synaptic connections has been proposed to be the major mechanism of learning in both vertebrate and invertebrate systems (Milner et al., 1998; Kandel, 2001). Changes in the strength of excitatory synaptic connections have been the major focus of attention but there is increasing evidence that modification of inhibitory synaptic mechanisms are also involved in memory (e.g., Kojima et al., 1997; Hansel et al., 2001). In gastropod molluscs there are a number of examples of learning-induced changes in both inhibitory and excitatory synaptic connections. Indeed, interactions between these two types of changes have been shown to be important in both sensitization (Trudeau and Castellucci, 1993, Aplysia gill and siphon withdrawal reflex) and classical conditioning (Davis et al., 1983, Pleurobranchaea feeding; Crow and Tian, 2006, Hermissenda phototaxis).

In the present study, we focused on the role of inhibition in reward classical conditioning in the feeding system of the pond snail, Lymnaea stagnalis. This mollusc has been extensively used to study the neuronal and molecular basis of associative memory formation (Benjamin et al., 2000; Benjamin and Kemenes, 2009). A previously proposed mechanism for the increased feeding response to the CS after one-trial chemical conditioning relies on an enhanced excitatory synaptic response recorded in cerebral command-like neurons (cerebrobuccal interneurons, CBIs) that activate the feeding central pattern generator (CPG) (Kemenes et al., 2006). Now we examine an additional mechanism that might underlie the conditioned response that reduces the tonic inhibitory synaptic modulation of the CPG. This type of tonic or maintained inhibition is known to suppress feeding in quiescent animals in the absence of food or in satiated animals (Staras et al., 2003) but its modulation could also play a role in learning. We hypothesize that if the tonic inhibition is reduced by conditioning then it would make the feeding CPG and the CPG-driven motoneurons more easily activated by the CS. The inhibitory synaptic input that modulates feeding is known to originate from a CPG interneuron known as N3t. This N3t neuron has a monosynaptic inhibitory connection with N1M (Figure 1), a CPG interneuron whose required activation to produce a feeding rhythm depends on a reduction of N3t tonic inhibition (Staras et al., 2003). The reduction in the N3t inhibitory input leads to plateauing activity in the N1M and subsequent firing in the N2 and N3 CPG interneurons that fire in sequence (N1, N2, and N3) to drive a three phase feeding rhythm in the motoneurons. Under these circumstances the N3t fires phasically and becomes part of the CPG rhythm.

We use an in vitro version of the one-trial chemical conditioning procedure (Marra et al., 2006; Harris et al., 2010) to monitor changes in the frequency of N3t tonic activity in the first few hours after conditioning. We show that there is a reduction in the $\mathrm{N} 3 \mathrm{t}$ 
firing frequency at 1, 2, 3, and $4 \mathrm{~h}$ but not at 10 and 30 min after conditioning and this reduction correlates with an increase in the conditioned feeding response to the CS. Computer simulations based on a previously published model of the feeding network (Vavoulis et al., 2007) support the conclusion that the reduced level of tonic inhibition plays an important role in Lymnaea reward conditioning.

\section{MATERIALS AND METHODS IN VITRO CONDITIONING AND ELECTROPHYSIOLOGICAL RECORDING}

Adult L. stagnalis, were raised in the breeding facilities at the University of Sussex. Animals were starved for 3 days and dissected to obtain a semi-intact preparation. This consisted of the entire CNS and chemo-sensory structures (i.e., lips and esophagus) as described by Straub et al. (2006) (Figure 2). The preparations were perfused with normal snail saline (NS) containing $50 \mathrm{mM} \mathrm{NaCl}$, $1.6 \mathrm{mM} \mathrm{KCl}, 2 \mathrm{mM} \mathrm{MgCl}, 3.5 \mathrm{mM} \mathrm{CaCl}_{2}, 10 \mathrm{mM}$ HEPES buffer in water. The semi-intact preparations were conditioned by perfusing the lips with $0.27 \mathrm{mM}$ amyl acetate (CS) in NS for $2 \mathrm{~min}$, immediately followed by $2 \mathrm{~min}$ of $0.27 \mathrm{mM}$ amyl acetate applied to the lips together with $20 \mathrm{mM}$ sucrose (US) perfused to both lips and esophagus. The conditioned response was tested by perfusing the lips with the CS for 2 min and measuring the electrophysiological response in the $\mathrm{B} 3$ motoneuron at various time points $(10,30 \mathrm{~min}$, 1,2 , and $3 \mathrm{~h}$ ) after the one-trial conditioning. The B3 motoneurons can be identified because of their large size and unique location on the surface of the buccal ganglia (Benjamin and Rose, 1979). B3 motoneurons were recorded using sharp electrodes (20-40 M $\Omega$ ) filled with $4 \mathrm{M}$ potassium acetate. NL 102 (Digitimer Ltd) and Axoclamp 2A (Axon Instrument, Molecular Device) amplifiers were used and data were acquired using a micro $1401 \mathrm{Mk}$ II interface and analyzed using Spike 2 software (Cambridge Electronic Design, Cambridge, UK).

The B3 motoneurons were recorded because they act as a monitor of N3t firing (see Staras et al., 2003). Spikes in the N3t cells generate 1:1 monosynaptic EPSPs on the B3s (Rose and Benjamin, 1979; Elliott and Benjamin, 1985) and can therefore be used an indirect method for recording N3t firing rates (circuit shown in Figure 1). The N3t cells are small and difficult to record in every preparation making it more convenient to monitor N3t firing in the B3 motoneurons. The B3s were also used to measure fictive feeding responses to application of the CS. Fictive feeding consists of bursts of spikes in motoneurons like the B3s that correspond to feeding cycles in the intact animal (Rose and Benjamin, 1979). Fictive feeding responses were calculated as a difference score by subtracting the number of B3 bursts in the 2-min before application of the CS from the number occurring in the 2-min after application of the CS. Other types of analysis were also carried out, including measuring the effect of conditioning on the duration of fictive feeding bursts.

\section{COMPUTATIONAL MODELING}

A computational model was used to simulate the effects of varying $\mathrm{N} 3 \mathrm{t}$ firing frequency on the probability of firing of the N1Ms. The analysis was based on previously published models of the feeding CPG interneurons of L. stagnalis (Vavoulis et al., 2007). The N1M model neuron was continuously stimulated by injecting a constant

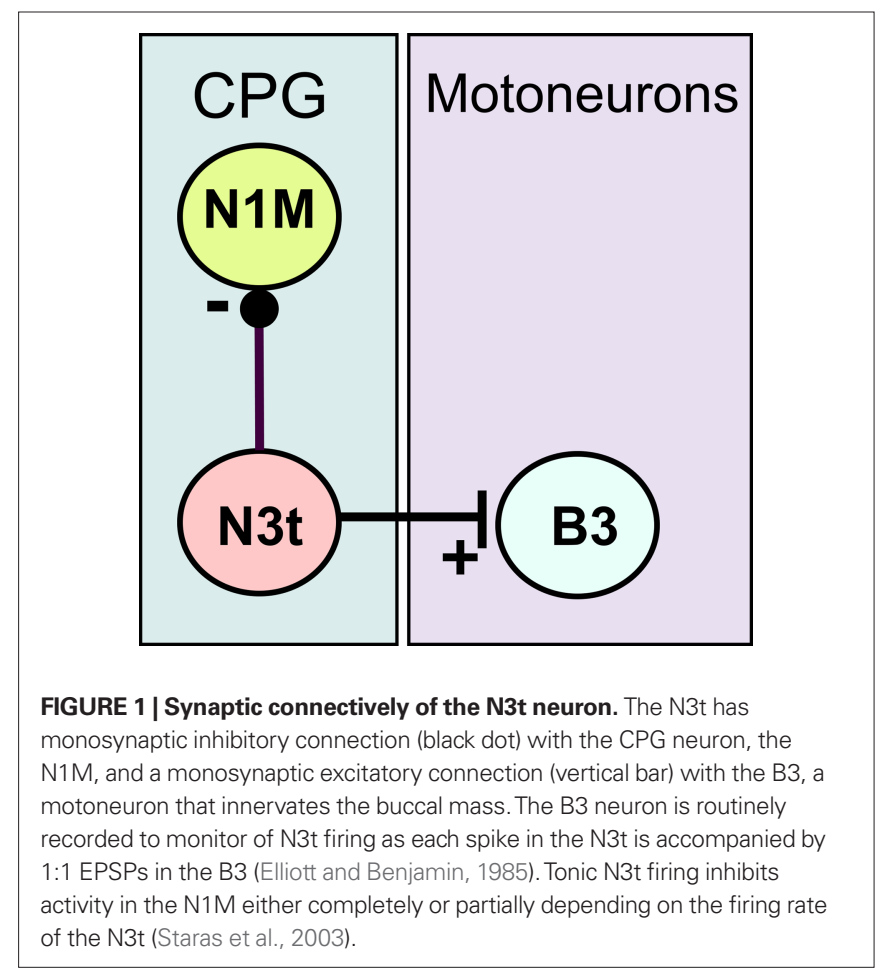

excitatory current of $0.4 \mu \mathrm{A} / \mathrm{cm}^{2}$ and the frequency of N3t firing was varied between 1 and $5 \mathrm{~Hz}$. The N3t inhibitory inputs on N1M were stochastically simulated assuming that $\mathrm{N} 3 \mathrm{t}$ spike generation is a random Poisson process and that each $\mathrm{N} 3 \mathrm{t}$ spike induces an IPSC on N1M with maximal conductance $0.15 \mathrm{mS} / \mathrm{cm}^{2}$, reversal potential $-75 \mathrm{mV}$ and synaptic activation described by an alpha function with a time constant equal to $40 \mathrm{~ms}$. These values were chosen such that N3t-induced IPSPs on N1M are of similar amplitude and duration in both the model and biological neurons. The model was numerically solved using an exponential Euler integration method with constant time step equal to $0.005 \mathrm{~ms}$. For each simulation only the first $1000 \mathrm{~ms}$ were analyzed.

\section{DATA ANALYSIS}

The frequency of N3t excitatory inputs recorded on the B3 motoneurons was measured at different time points from the beginning of the recording. The traces were visualized off-line using Spike2 and the frequency was sampled for at least $30 \mathrm{~s}$ of recording using a Spike2 script. The duration of the CS induced feeding cycles in the B3 motoneurons was similarly measured off-line. The control groups used are constituted of preparations presented with either CS alone or US alone, no statistical difference could be observed between these two types of control treatment (Student's $t$-test, $P>0.05$; CS alone, $n=6$; US alone, $n=5$ ). The comparisons between groups have been carried out using either $t$-test or a one-way analysis of variance (1-way ANOVA) followed by Newman-Keuls test. Values of $P<0.05$ are indicated with a single asterisk $\left(^{*}\right)$, values of $P<0.01$ a double asterisk $\left({ }^{* *}\right)$ and values of $P<0.001$ with a triple asterisk ${ }^{* * *}$ ). Correlations between data sets were studied using Pearson's correlation test. Statistical analyses were carried out using either Prism (Graphpad Software) or R (R-project) software. 


\section{RESULTS}

\section{N3t TONIC FIRING RATE IS DECREASED AFTER CONDITIONING}

To test whether learning leads to a change in the firing rates of the $\mathrm{N} 3 \mathrm{t}$ cell, the frequency of N3t synaptic inputs were recorded in the B3 motoneurons before and after a single pairing of the CS and US in the semi-intact preparation (Figure 2). Figure 3A is an example of intracellular recording from a B3 motoneuron showing N3t EPSP inputs in experimental and control preparations. The top trace shows the N3t-induced EPSPs observed before pairing and the middle trace $3 \mathrm{~h}$ after pairing. A clear reduction in the frequency of N3t inputs occurs. Figure 3B shows the more quantitative analysis where the N3t

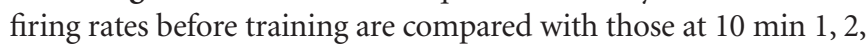
and $3 \mathrm{~h}$ after pairing $(n=11)$. The repeated measurement ANOVA indicates a source of significant difference $[F(4,40)=4.9, P<0.01]$ in the data and the post hoc analysis indicates a significant reduction in the N3t input frequency at 1,2 , and $3 \mathrm{~h}$ after pairing compared with before (Newman-Keuls post hoc $P<0.05$ ). However, no statistical difference was observed between the N3t input frequency before and 10 min after pairing $(P>0.05)$.

A further set of more detailed experiments were carried out where N3t spontaneous firing rates were measured in an experimental paired group (CS + US) and compared with controls. B3 motoneurons were recorded in preparations at $30 \mathrm{~min}$ and $4 \mathrm{~h}$ after conditioning as well as at $10 \mathrm{~min}, 1,2$, and $3 \mathrm{~h}$ to provide a more complete time-course of learning-induced N3t firing changes. An example of an intracellular recording from a B3 in a control preparation is shown in Figure 3A (bottom trace). The frequency of the N3t inputs at $3 \mathrm{~h}$ in this control preparation is higher than the one observed in a paired preparation at the same time point after conditioning. The histogram in Figure 3C provides a statistical analysis of N3t firing in the paired and control preparations at different time points after conditioning. The data for each time point are obtained from a different group of preparations. The ANOVA showed source of difference $[F(1,122)=6.1, P<0.0001]$ between the groups. Further comparison between paired and control groups at each time point were made using a Newman-Keuls test. Comparisons of data from paired and control preparations at a particular time-point showed a significant difference at $1,2,3$, and $4 \mathrm{~h}(1 \mathrm{~h}$ paired vs $1 \mathrm{~h}$ control
$P<0.01, n=15, n=11$, respectively; $2 \mathrm{~h}$ paired vs $2 \mathrm{~h}$ control $P<0.05$, $n=14, n=11$, respectively; $3 \mathrm{~h}$ paired vs $3 \mathrm{~h}$ control $P<0.05, n=14$, $n=11$, respectively; 4 h Paired vs $4 \mathrm{~h}$ control $P<0.01, n=11, n=12$, respectively) but not at 10 and $30 \mathrm{~min}$ (10 min paired vs $10 \mathrm{~min}$ control $P>0.05, n=9, n=11$, respectively; 30 min paired vs $30 \mathrm{~min}$ control $P>0.05, n=7, n=8$, respectively). The mean level of N3t firing was maintained in control preparations over the $1-4 \mathrm{~h}$ period of the experiment (Figure 3C) indicating that the reduction in the frequency observed in the paired groups over the same time period was not due to preparation "run down."

\section{APPLICATION OF THE CS DOES NOT CHANGE THE FREQUENCY OF N3t FIRING}

The frequency of N3t firing was measured for $30 \mathrm{~s}$ prior to CS application and compared with firing for 30 seconds during the CS application in trained preparations. There was no statistical difference between the two scores (Student's $t$-test, $P>0.05$ ) (Figure 4) indicating that application of the CS does not influence the level of firing of the N3ts in conditioned preparations.

\section{INVERSE CORRELATION BETWEEN FICTIVE FEEDING RESPONSE AND N3t FREOUENCY AFTER CONDITIONING DEPENDS ON ACTIVATION OF THE CS PATHWAY}

The N3t frequency before CS application was compared with the conditioned fictive feeding response measured as a difference score (see Materials and Methods). Plotting the N3t input frequency against of fictive feeding cycles revealed a significant inverse correlation $(r=-0.7$, $P<0.05, n=10$ ) at the 4 -h time point (Figure 5A). Interestingly, the number of background fictive feeding cycles observed in the 2-min preceding the CS test is not correlated with the N3t frequency $(r=-0.1$, $P>0.05, n=10$ ) (Figure 5B). This suggests that the conditioned fictive feeding response depends not only on changes in the N3t firing rate but also on additional changes in the CS pathway.

\section{DELAYED REDUCTION IN CYCLE DURATION AFTER CONDITIONING}

A comparison of CS-induced fictive feeding cycles at different time points after conditioning indicated that their mean duration was significantly reduced at 1,2 , and $4 \mathrm{~h}$ compared

\section{Pre-Conditioning}

Post-Conditioning
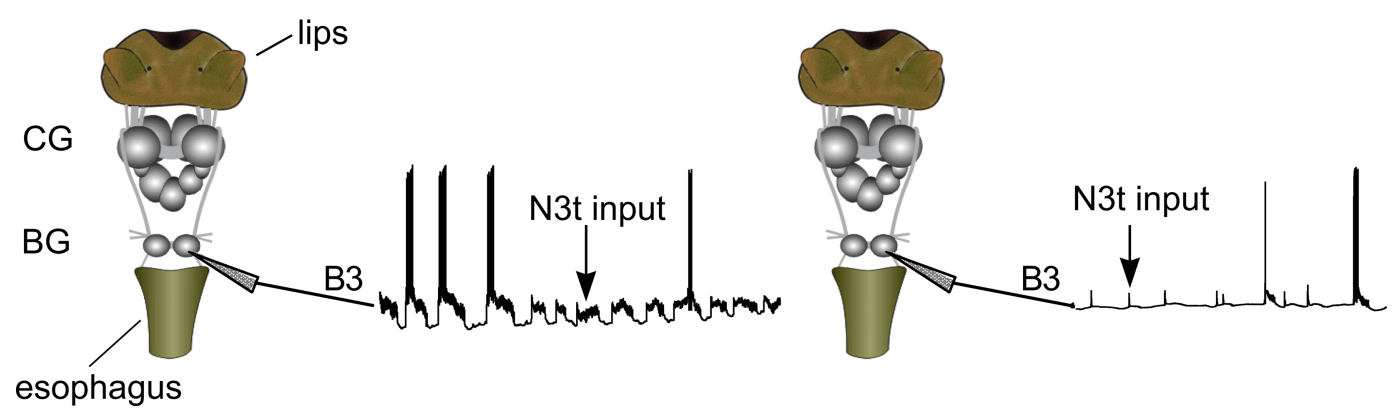

FIGURE 2 |The semi-intact preparation used to monitor the effects of conditioning on N3t activity. The preparation includes the whole CNS and the chemosensory sensory structures involved in the feeding response (lips and esophagus). The B3 is located in the buccal ganglia (BG) and other parts of feeding circuitry are located in the cerebral ganglia (CG). The monosynaptic EPSP inputs of N3t on the B3 motoneurons were monitored at $3 \mathrm{~h}$ before and after conditioning. A reduction in the frequency of the post-synaptic input can be observed after conditioning. 
A

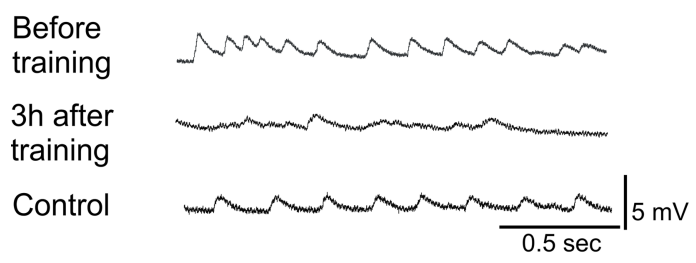

C
B

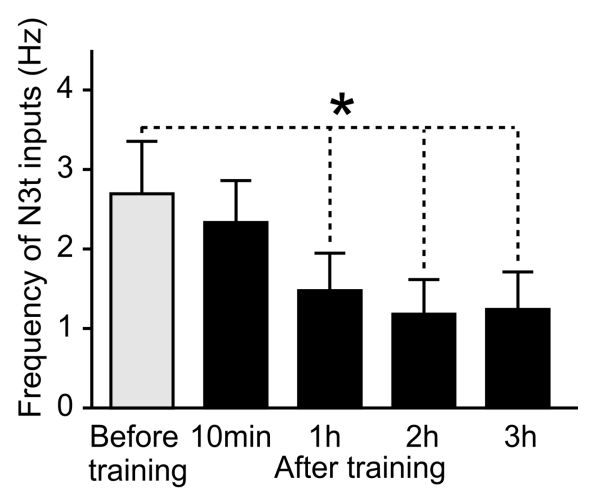

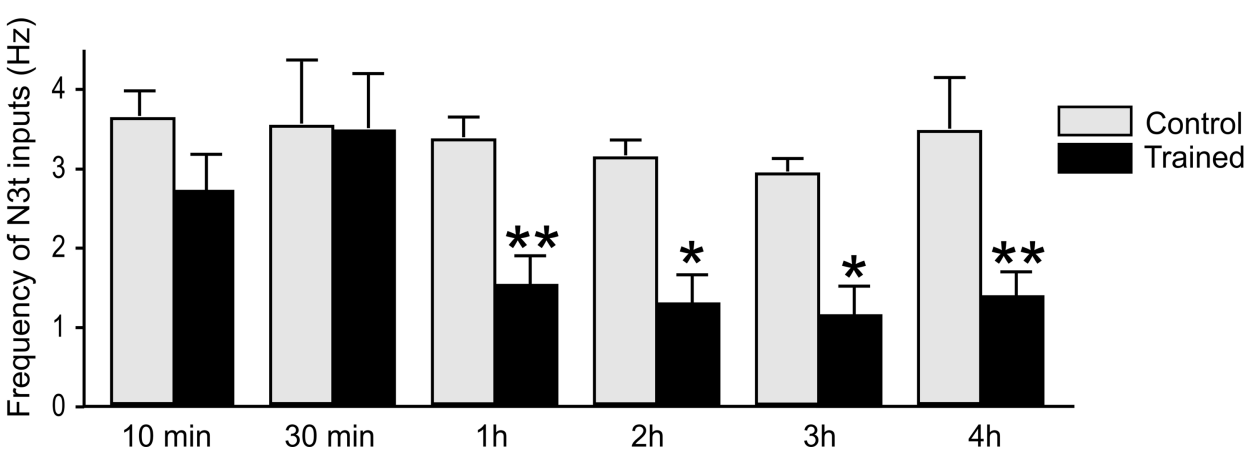

FIGURE 3 | Reduction in N3t frequency following single-trial conditioning. (A) Intracellular recordings showing examples of N3t synaptic inputs on B3 motoneurons. The top trace shows the N3t-driven inputs before pairing, the middle trace, a B3 motoneuron $3 \mathrm{~h}$ after pairing. The frequency of the N3t inputs is lower than before pairing. The bottom trace is an intracellular recording of a B3 motoneuron from a control preparation at the 3-h time point. The frequency of the N3t inputs in control preparations is higher than in the experimental preparation at the same time point, and similar to the frequency before pairing. (B) The N3t frequency is compared at various time points before and after pairing. At 1, 2, and $3 \mathrm{~h}$ after pairing the paired group are significantly lower than before pairing, but there is no statistical difference at $10 \mathrm{~min}$ after pairing (see text for detailed statistical analysis). (C) Comparison of the N3t firing frequency in paired and control groups of preparations at different time points after conditioning. There are significant difference between paired and control groups at 1, 2, 3, and $4 \mathrm{~h}$ conditioning but not at 10 and $30 \mathrm{~min}$ (see text for statistics).

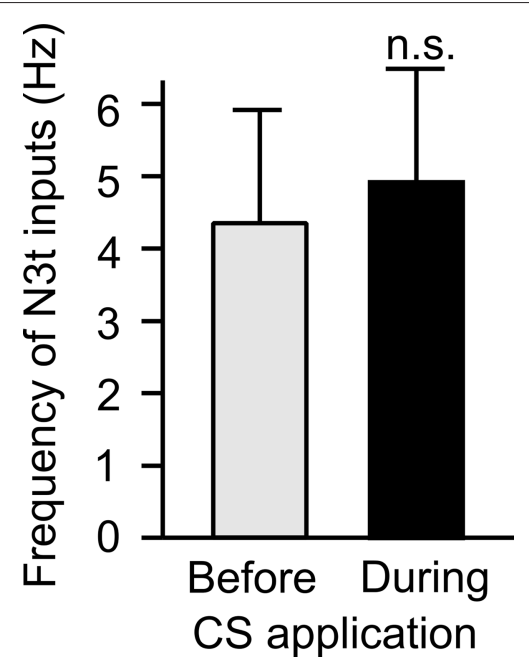

FIGURE 4 | CS application does not change the frequency of the N3t inputs on the B3. The frequency of N3-driven EPSPS on the B3 was measured immediately before and during CS application following pairing. The data from eight preparations tested at different time points after pairing were combined, no statistically significant difference can be observed using a two-tailed paired $t$-test $(P>0.05)$ with $10 \mathrm{~min}$ (Figure 6). An initial ANOVA showed a source of difference $[F(3,63)=5.85, P<0.001]$ between the groups and a post hoc test showed a significant difference between the 10 -min time point $(n=11)$ compared with each of the later time points (Newman-Keuls post hoc test $10 \mathrm{~min}$ vs $1 \mathrm{~h}$ $P<0.01, n=14 ; 10 \mathrm{~min}$ vs $3 \mathrm{~h} P<0.001, n=28 ; 10 \mathrm{~min}$ vs $4 \mathrm{~h}$ $P<0.01, n=13)$.

\section{COMPUTATIONAL MODELING SUGGESTS THAT REDUCING N3t FIRING INCREASES THE PERCENTAGE OF PREPARATIONS SHOWING N1M FIRING}

To further investigate the effect of reducing the N3t activity on the generation of a feeding cycle, we performed computer simulations based on a previously published computational model of the relevant feeding CPG interneurons (Vavoulis et al., 2007). The computer model allowed us to manipulate the frequency of N3t and test whether lowering N3t firing frequency was sufficient to induce activation of the N1M from a previously sub-threshold stimulus. A constant depolarizing current was injected into the model N1M at different mean firing frequencies of N3t. The model predicts that the percentage of preparations showing N1M bursting is highest when the N3t is firing at its lowest rate $(1 \mathrm{~Hz})$ and rapidly decreases as the firing rate is progressively increased to 


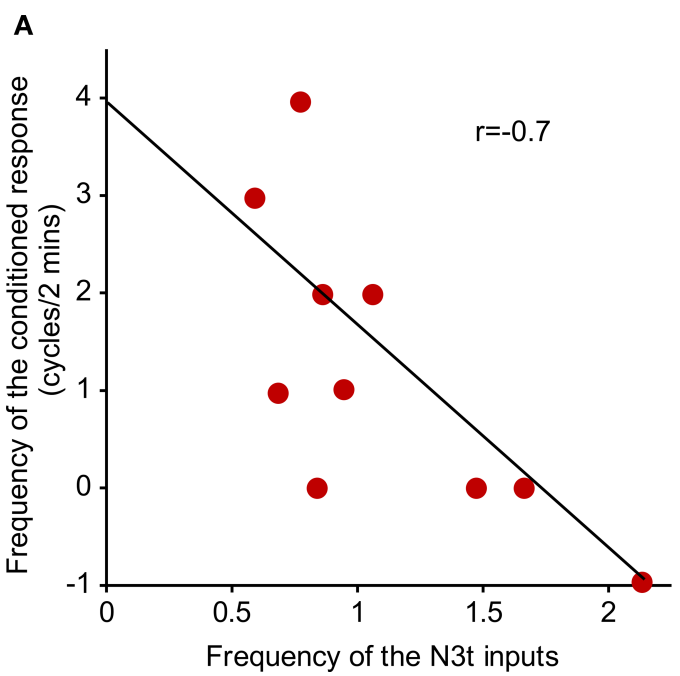

FIGURE 5 | Inverse correlation between N3t firing rate and frequency of fictive feeding response. (A)The N3t frequency before CS application was compared with the conditioned fictive feeding response measured as a difference score. There is a

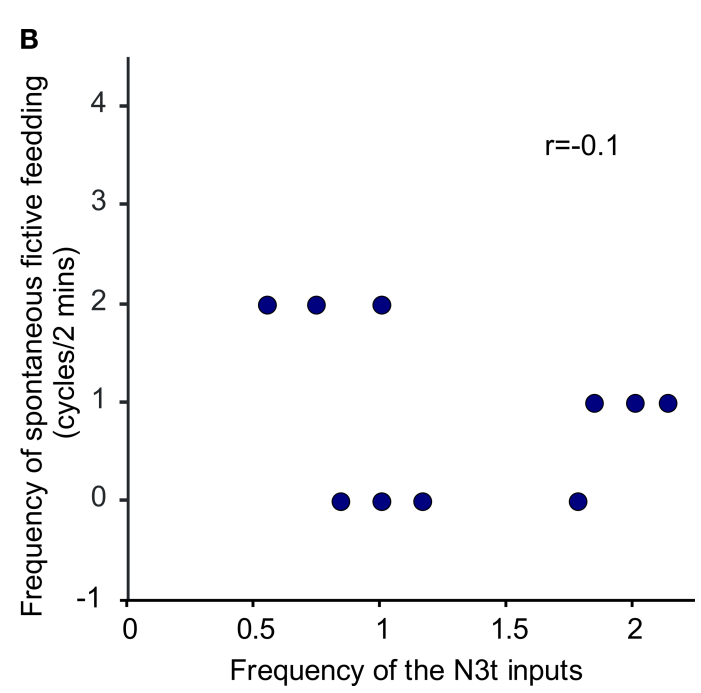

significant inverse correlation ( $r=-0.7, P<0.05, n=10)$ at the 4 -h time point. (B) The number of background fictive feeding cycles observed in the 2-min preceding the CS test is not correlated with the N3t frequency $(r=-0.1, P>0.05, n=10)$.

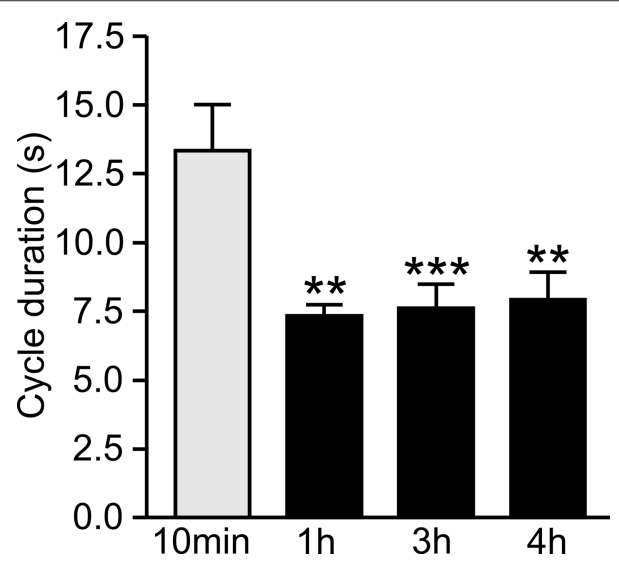

FIGURE 6 | Delayed decrease in fictive feeding cycle duration after conditioning. The duration of fictive feeding cycles at 1, 2, and $3 \mathrm{~h}$ after pairing were compared with the duration at $10 \mathrm{~min}$ after pairing. There is a statistically significant reduction at the 1,2, and $3 \mathrm{~h}$ time points compared with $10 \mathrm{~min}$ (see text for statistics) but no other significant difference between the groups.

$5 \mathrm{~Hz}$ (Figure 7). Generation of a burst of spikes in the N1M is a reasonable assay of "preparation responsiveness" since in the biological system spike activity in the N1M is always accompanied by rhythmic spike activity in the rest of the CPG network (Elliott and Benjamin, 1985) and this drives rhythmic fictive feeding activity in motoneurons like the B3.

\section{DISCUSSION}

The main result from these experiments is that the frequency of tonic N3t firing is reduced following single-trial in vitro chemical conditioning. The reduction level was observed at $1 \mathrm{~h}$ after

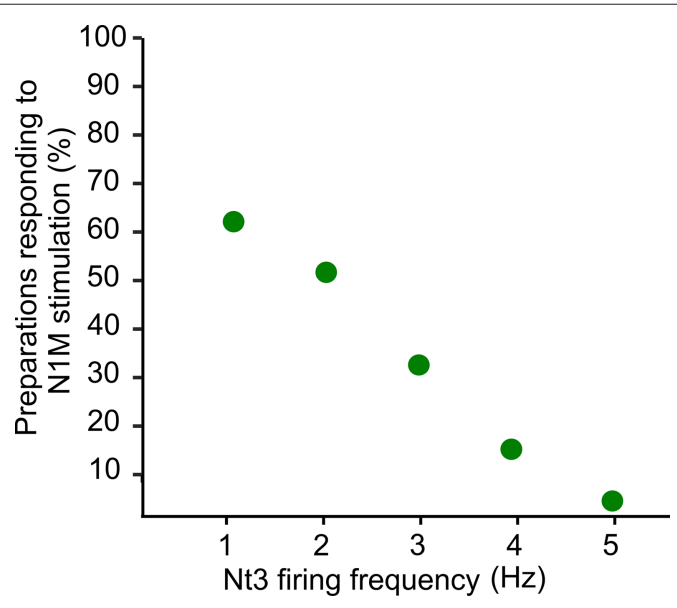

FIGURE 7 | Computer simulation of N3t firing frequency and preparation responsiveness. A constant depolarizing current was injected into the model N1M at different firing frequencies of the N3t. Whether the N1M

("preparation") responded by generating a burst of action potentials to the depolarizing stimulus depended on the firing rate of the N3t. The preparations were more likely to respond when N3t is firing at its lowest rate $(1 \mathrm{~Hz})$ and responsiveness rapidly decreased as the firing rate is progressively increased to $5 \mathrm{~Hz}$. Spike activity in the N1M in the biological network is a reliable indicator of activation of the whole CPG network and the feeding ingestive rhythm.

conditioning and up to $4 \mathrm{~h}$ but did not occur at the earlier time points of 10 and $30 \mathrm{~min}$. Importantly, the frequency of the N3t input is inversely correlated with the strength of the conditioned response, i.e., the conditioned response measured as changes in the fictive feeding response to the CS is stronger in preparations displaying a lower level of inhibition. Application of the CS did not change the frequency of $\mathrm{N} 3 \mathrm{t}$ firing so conditioning reduces 
the "background" level of N3t firing. The N3t cells monosynaptically inhibit the most important CPG interneuron, the N1M (see Figure 1), and it is this inhibitory synaptic connection that mediates the inhibitory effects of the N3t firing on the rhythmic activity underlying fictive feeding activity (shown in Staras et al., 2003). We suggest a permissive role for the learning-induced reduction in background inhibition, lowering the threshold for activation of the feeding CPG by the CS. This can be considered as part of the memory trace for reward conditioning. It cannot be important for the earliest phase of memory formation ("short-term memory") because no changes in N3t firing rate were recorded in the first hour after conditioning. A second type of change produced by conditioning was the reduction in the duration of the fictive feeding cycles at 1,2 , and $3 \mathrm{~h}$ after pairing compared with $10 \mathrm{~min}$. From previous work (Staras et al., 2003) we know that duration of motoneuron cycles is correlated inversely with the frequency of feedback inhibition from the N3ts to the N1Ms so bursts are longer in duration when inhibitory feedback is reduced. After conditioning, reduction in N3t firing rate occurs at 1,2,3, and $4 \mathrm{~h}$ but not at $10 \mathrm{~min}$ (Figure 3 ) so this can account for burst duration being greater at $10 \mathrm{~min}$ than the later time-points.

It is important to note that the results from the present experiments were obtained in preparations made from hungry snails. Earlier work by Staras et al. (2003) in naïve snails showed that firing rates in the $\mathrm{N} 3 \mathrm{t}$ cells and their consequent inhibitory modulation of feeding was dependent on their level of hunger and satiety. Hungry snails had significantly lower levels of maintained N3t firing (inhibition) than preparations made from satiated snails. However the reductions in $\mathrm{N} 3 \mathrm{t}$ firing due to learning were greater $(1-2 \mathrm{~Hz})$ than the maximum produced by hunger alone $(2-3 \mathrm{~Hz})$. This is an important result because it indicates that the effects of learning are greater than motivation factors such as hunger and satiety.

Our results do not give any information on the mechanisms underlying the change in N3t activity. For instance, whether they involve changes in the intrinsic properties of the neuron and/or synaptic inputs from other interneurons in the feeding network. However, the results do indicate that the likely location of the learning-induced changes is in the buccal ganglia. The N3t cells and their target B3 and N1M neurons are located in this part of the feeding system with their anatomy and synaptic connectivity restricted to these paired ganglia (Elliott and Benjamin, 1985). Previous work showed that higher-order modulatory neurons in the cerebral ganglia provide another site for electrical changes following one-trial chemical conditioning (Straub et al., 2004; Kemenes et al., 2006). The cerebral mechanism produces an enhanced excitatory synaptic response in the CBIs due to a $\mathrm{Ca}^{2+}$-dependent pre-synaptic facilitation of the CS to CBI pathway by the modulatory Cerebral Giant Cells (Kemenes et al., 2006). However, this excitatory mechanism was first observed at 16-24 h after conditioning and so may not interact temporally with the inhibitory mechanism described in the present paper which so far has only been observed from 1 to $4 \mathrm{~h}$ after conditioning. However, there must be some independent change in the CS pathway in the 1-4 h time period because the correlation between $\mathrm{N} 3 \mathrm{t}$ firing and the conditioned fictive feeding response requires the application of the CS and cannot be due solely to a reduction in background $\mathrm{N} 3 \mathrm{t}$ firing.

Interactions between excitatory and inhibitory synaptic changes induced by classical conditioning have been described in several invertebrate systems (Davis et al., 1983; Crow and Tian, 2006). The results from aversive classical conditioning of feeding Pleurobranchaea are of particular interest because they involve learning-induced changes in background synaptic inputs in the paracerebral (phasic type) command cells in naïve animals. Conditioning changes the balance of "spontaneous" inhibitory and excitatory synaptic inputs to the command neurons so that the preparations show a decreased level of excitatory inputs and an increased level of inhibitory inputs on application of the CS (food or touch), reducing the ability of the paracerebral cells to activate feeding. Davis et al. (1983) also examined the effects of hunger and satiety on the response to food stimuli and found

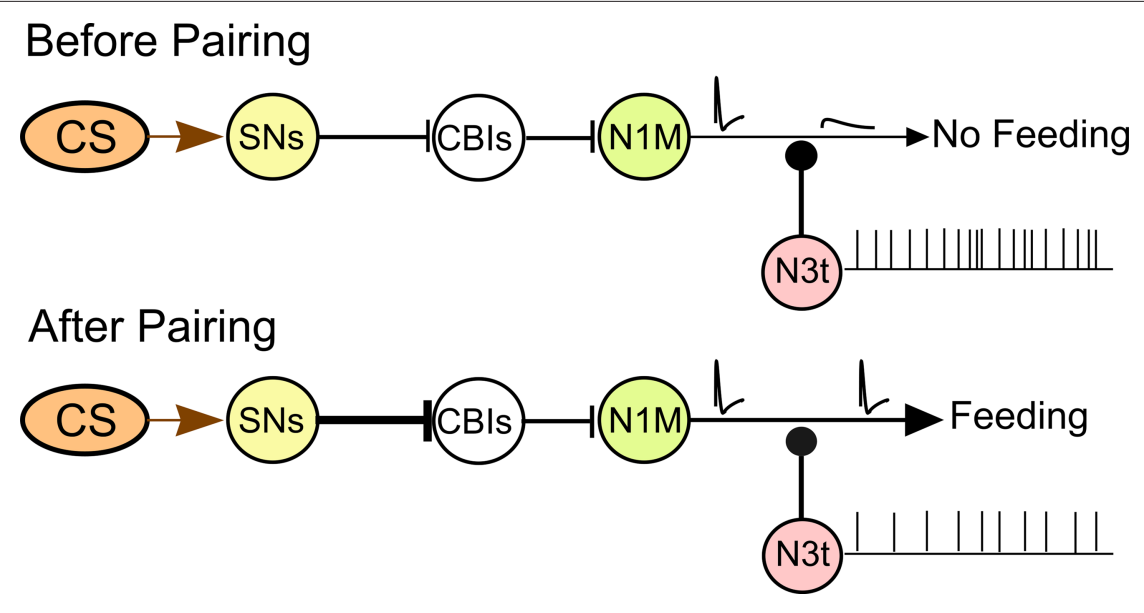

FIGURE 8 | Circuit model for the CS-induced activation of the feeding CPG. The diagram summarizes the current knowledge of the pairing-induced cellular changes in the CNS. The CS pathway does not produce a behavioral response before pairing and only attenuated (blocked) spikes are conducted to the distal axonal regions of the N1M. Following pairing the CS triggers a feeding response. A strengthening of the excitatory pathway is proposed between the CS sensory pathway and the CBIs. Conditioning reduces N3t inhibition of the N1M bringing it closer to the threshold potential for firing with full sized spikes present in the N1M distal axon (see text for further discussion). 
that satiated animals responded in the same way as aversively conditioned animals, i.e., the balance of inhibition/excitation was changed in favor of inhibition. However, unlike Lymnaea where training produced greater changes in background inhibition than hunger and satiety, the effects of satiety appear to be similar (or greater) in strength to those due to learning.

We present a circuit-level model of the Lymnaea feeding pathway before and after one-trial chemical conditioning (Figure 8) based on previously published data on the feeding network and its chemosensory inputs (Straub et al., 2004, 2006; Kemenes et al. 2006). The CS pathway has no effect on feeding before pairing. Following pairing the CS triggers a feeding response. The feeding response is generated through the sensory neuron (SN), CBI, N1M pathway. Evidence exists that the excitatory SN to CBI synapse is enhanced after conditioning (Straub et al., 2004). Conditioning also reduces spike activity in the $\mathrm{N} 3 \mathrm{t}$ interneuron therefore reducing the inhibition of the N1M making it more likely to respond to the $\mathrm{CS}$. Once the N1M starts firing it drives activity in the rest of the CPG network (Staras et al., 2003). The model is consistent with the results of computer simulations presented in this study. The

\section{REFERENCES}

Benjamin, P. R., and Kemenes, G. (2009). "Invertebrate models to study learning and memory: Lymnaea," in Encyclopedia of Neuroscience, Vol.5, ed. L. Squire (Oxford: Academic Press), 197-204.

Benjamin, P. R., and Rose, R. M. (1979). Central generation of bursting in the feeding system of the snail, Lymnaea stagnalis. J. Exp. Biol. 80, 93-118.

Benjamin, P. R., Staras, K., and Kemenes, G. (2000). A systems approach to the cellular analysis of associative learning in the pond snail Lymnaea. Learn. Mem. 7, 124-131.

Crow, T., and Tian, L. M. (2006). Pavlovian conditioning in Hermissenda: a circuit analysis. Biol. Bull. 210, 289-297.

Davis, W. J., Gillette, R., Kovac, M. P., Croll, R. P., and Matera, E. M. (1983). Organization of synaptic inputs to paracerebral feeding command interneurons of Pleurobranchaea californica. III. Modifications induced by experience. J. Neurophysiol. 49, 1557-1572.

Debanne, D. (2004). Information processing in the axon. Nat. Rev. Neurosci. 5, 304-316.

Elliott, C. J., and Benjamin, P. R. (1985). Interactions of pattern-generating interneurons controlling feeding in Lymnaea stagnalis. J. Neurophysiol. 54, 1396-1411.
Evans, C. G., Jing, J., Rosen, S. C., and Cropper, E. C. (2003). Regulation of spike initiation and propagation in an Aplysia sensory neuron: gating-in via central depolarization. J. Neurosci. 23, 2920-2931.

Hansel, C., Linden, D. J., and D'Angelo, E. (2001). Beyond parallel fiber LTD: the diversity of synaptic and nonsynaptic plasticity in the cerebellum. Nat. Neurosci. 4, 467-475.

Harris, C. A., Passaro, P. A., Kemenes, I., Kemenes, G., and O'Shea, M. (2010). Sensory driven multi-neuronal activity and associative learning monitored in an intact CNS on a multielectrode array. J. Neurosci. Methods 186, 171-178.

Kandel, E. R. (2001). The molecular biology of memory storage: a dialogue between genes and synapses. Science 294, 1030-1038.

Kemenes, I., Straub, V. A., Nikitin, E. S., Staras, K., O'Shea, M., Kemenes, G., and Benjamin, P. R. (2006). Role of delayed nonsynaptic neuronal plasticity in long-term associative memory. Curr. Biol. 16, 1269-1279.

Kojima, S., Nanakamura, H., Nagayama, S., Fujito, Y., and Ito, E. (1997). Enhancement of an inhibitory input to the feeding central pattern generator in Lymnaea stagnalis during conditioned taste-aversion learning. Neurosci. Lett. 230, 179-182.

simulations suggest that changes in N3t firing frequency, within the experimentally observed range, are sufficient to change the probability of activation of the N1M. We hypothesize that the location of the N3t to N1M synapse is on the axonal region of the N1M. Small changes in membrane potential have been shown to affect the propagation of the action potential between two different sections of a neurite in both vertebrates and invertebrates (Evans et al., 2003; Debanne, 2004) and we suggest that this might be occurring in the N1M cell so that attenuated spikes in the distal N1M axon before pairing would be propagated as full spikes after conditioning. The model emphasizes that chemical reward conditioning is likely to involve changes in synaptic strength at a number of different sites in the network.

\section{ACKNOWLEDGMENTS}

Vincenzo Marra was supported by the UK EPSRC, Paul R. Benjamin, Michael O'Shea, and Ildikó Kemenes by the UK BBSRC, and Dimitris Vavoulis and Jianfeng Feng by the Future and Emerging Technologies (FET) European Commission program BION (number 213219).

Marra, V., Ireland, J. S., Kemenes, I., Straub, V.A., O'Shea, M., and Benjamin, P. R. (2006). "In-vitro one-trial reward conditioning in the pond snail Lymnaea," in Neuroscience Meeting Planner. Atlanta, GA: Society for Neuroscience, 669.18.

Milner, B., Squire, L. R., and Kandel, E. R. (1998). Cognitive neuroscience and the study of memory. Neuron 20, 445-468.

Rose, R. M., and Benjamin, P. R. (1979) The relationship of the central motor pattern to the feeding cycle of Lymnaea stagnalis. J. Exp. Biol. 80, 137-163.

Staras, K., Kemenes, I., Benjamin, P. R. and Kemenes, G. (2003). Loss of selfinhibition is a cellular mechanism for episodic rhythmic behavior. Curr. Biol. 13, 116-124.

Straub, V.A., Kemenes, I., O'Shea, M., and Benjamin, P. R. (2006). Associative memory stored by functional novel pathway rather than modifications of pre-existing neuronal pathways. $J$. Neurosci. 26, 4139-4146.

Straub, V. A., Styles, B. J., Ireland, J. S. O'Shea, M., and Benjamin, P. R. (2004). Central localization of plasticity involved in appetitive conditioning in Lymnaea. Learn. Mem. 11, 787-793.

Trudeau, L. E., and Castellucci, V. F. (1993). Sensitization of the gill and siphon withdrawal reflex of Aplysia: multiple sites of change in the neuronal network. J. Neurophysiol. 70, 1210-1220.

Vavoulis, D. V., Straub, V. A., Kemenes, I., Kemenes, G., Feng, J., and Benjamin, P. R. (2007). Dynamic control of a central pattern generator circuit: a computational model of the snail feeding network. Eur. J. Neurosci. 25, 2805-2818.

Conflict of Interest Statement: The authors declare that the research was conducted in the absence of any commercial or financial relationships that could be construed as a potential conflict of interest.

Received: 28 May 2010; paperpending published: 03 August 2010; accepted: 15 August 2010; published online: 15 September 2010.

Citation: Marra V, Kemenes I, Vavoulis $D$, Feng J, O'Shea $M$ and Benjamin PR (2010) Role of tonic inhibition in associative reward conditioning in Lymnaea. Front. Behav. Neurosci. 4:161. doi:10.3389/ fnbeh.2010.00161

Copyright $(2010$ Marra, Kemenes, Vavoulis, Feng, O'Shea and Benjamin. This is an open-access article subject to an exclusive license agreement between the authors and the Frontiers Research Foundation, which permits unrestricted use, distribution, and reproduction in any medium, provided the original authors and source are credited. 